\title{
Transcriando Shakespeare: Palavra e/em Dança
}

\section{*Ines Saber de Mello **Nalu da Rocha ***Collin Luci}

\section{Resumo}

Este artigo apoia-se nos estudos de intermidialidade, transcriação de poesia, dança e literatura para fundamentar a transcriação do Soneto 12 de William Shakespeare. A palavra em cena potencializa através da corporeidade a expressão de discursos além do dizível. Ao cruzar teoria e prática é possível transformar as percepções corpóreas e o próprio entendimento poema. Ao pensar em fidelidade e transformação, esta produção emergiu como possibilidade de novas chaves de leitura do soneto, por aproximação e afastamento de seu tema raiz: o tempo. A reflexão corporal passa pela provisoriedade, permeabilidade e continuidade pela percepção do tempo, no poema, na dança e na condição humana.

Palavras-chave: intermidialidadetranscriação - dança e palavra - linguagem corporal

\begin{abstract}
This article is based on the intermediality studies, poetry transcreation, dance and literature to support the transcreation of William Shakespeare's Sonnet 12. The word in scene is empowered by corporeity and the expression of discourse beyond what is speakable. Crossing theory and practice it is possible to transform the bodily perceptions and the understanding of the poem itself. When reasoning about fidelity and transformation this production emerged as a possibility of bringing new reading opportunities of the sonnet, both in approaching and diverging of its root thematic: the time. The bodily reflexion goes through temporariness, permeability and continuity on the perception of time, on the poem, on dancing and on human condition.
\end{abstract}

keywords: intermediality - transcreation dance and word - body language

\footnotetext{
* Pesquisadora do Grupo de Pesquisa Literatura e Outras Artes, Cnpq/UFPR. E-mail: inessaber@gmail.com ** Pesquisadora do Grupo de Pesquisa Literatura e Outras Artes, Cnpq/UFPR.

*** Professora Associada no Departamento de Letras Estrangeiras Modernas da Universidade Federal do Paraná. Pesquisadora do Grupo de Pesquisa Literatura e Outras Artes, Cnpq/UFPR. E-mail: collinluci@gmail.com
} 
A partir da premissa de que o potencial interpretativo do universo textual não tem um limite, este artigo pretende investigar como a perspectiva cênica de um soneto pode permitir a sua expansão abrindo uma nova chave de leitura do poema: a percepção e transformação de ideias e hipóteses em movimento cênico, que partem da organização corpórea para levantamento de questões acerca da essência do Soneto 12 de William Shakespeare (1564-1616).

Como um autor clássico que há séculos gera um grande impacto estético em seu público, Shakespeare tem sido adaptado, traduzido e transcriado renovadamente para outras linguagens artísticas. Toda a obra shakespeariana evoca e ilumina a experiência humana e esta marca, que não se restringe ao drama, é franca também nos sonetos. Como a própria palavra indica, o "soneto" - do latim sonus, som - é uma forma lírica muito ligada ao aspecto melodioso e rítmico da linguagem. ${ }^{1}$

Dos 154 sonetos escritos por Shakespeare, o de n. 12 pertence ao grupo dos 17 primeiros em que o eulírico se dirige a um jovem tentando convencê-lo a se casar e a ter filhos a fim de que estes perpetuem a beleza do pai. Esse soneto mantém os catorze versos em que as doze primeiras linhas se dividem em três quartetos que apresentam o tema ou "problema" que é resolvido nas duas últimas linhas, no chamado dístico final (couplet). Os catorze versos mantêm os pentâmetros iâmbicos, versos de dez sílabas em que uma sílaba não acentuada é seguida por uma sílaba acentuada, como no exemplo do primeiro verso do original: When I / do count / the clock / that tells / the time. A estrutura rimática segue o padrão do soneto shakespeareano abab cdcd efef gg.

When I do count the clock that tells the time,

And see the brave day sunk in hideous night;

When I behold the violet past prime,

And sable curls all silver'd o'er with white;

When lofty trees I see barren of leaves

Which erst from heat did canopy the herd,

And summer's green all girded up in sheaves

Borne on the bier with white and bristly beard,

Then of thy beauty do I question make,

That thou among the wastes of time must go,

Since sweets and beauties do themselves forsake

And die as fast as they see others grow;

And nothing 'gainst Time's scythe can make defence

Save breed' to brave him when he takes thee hence. ${ }^{2}$

A palavra em poesia e, principalmente, num soneto, carrega uma grande carga emocional, típica da própria forma comprimida que é a expressão poética; as palavras no soneto - em que se mantém uma estrutura cerrada de versos, rimas e pés rítmicos - são elementos potentes, que caracterizam toda uma elaboração de sonoridade, a partir de sutilezas advindas de repetições, de acentos, de assonâncias e aliterações, todos eles recursos que criam uma rede sensorial amalgamada à rede semântica, de sentido. A palavra em cena é um produto, ou antes, um desdobramento, uma reverberação contínua desta primeira relação com a palavra do poema; a partir da experiência interpretativa da leitura, se desprende de outra leitura, já não do texto apenas, mas da "resposta" emocional ao texto, agora dada em uma reconfiguração artística e expressiva de novos códigos: o gesto, o corpo, a combinação de linhas, a respiração, a exploração do espaço e, naturalmente, a articulação de novos sentidos.

O soneto 12, ao tratar da finitude e da permanência/impermanência da natureza e do homem, abre-se em múltiplas redes de sentido ao ponto de ser ilimitado. Há uma identificação imediata com a realidade da 
existência humana, pois através de imagens trata a questão do passar do tempo no ciclo da vida. Dançar este soneto é a possibilidade latente de explorar corporalmente a infinitude shakespeariana e cultivar a palavra do poeta no século XXI.

Esclarecendo que não é o escopo do presente artigo listar produções artísticas e acadêmicas que vinculam palavra e dança, vimos antes refletir sobre a tradução/transcriação do Soneto 12 para a linguagem da dança. Buscamos, portanto, integrar teoria e prática, uma vez que aqui se faz a discussão do processo de tradução do soneto para a dança na produção própria das intérpretes criadoras, também coautoras deste artigo.

\section{Processo de inter-relações}

A criação cênica do Soneto 12 é um estudo de intermidialidade. Müeller (2010, p.22) afirma que a produção deste campo de estudo pode ser processos de intermídia de uma mídia específica, ou que apresenta interação entre vários dispositivos que criam outro produto. Este campo de estudo é a investigação das interrelações entre as artes. Situamos nossa pesquisa nesta categoria, uma vez que fundamenta-se na iluminação mútua das artes: o corpo como dança é iluminado pela palavra do soneto, enquanto o soneto é iluminado pela dança. É também uma tradução, por ser caracterizada pela representação de signos verbais em linguagem nãoverbal (JAKOBSON, 1999) e porque o objeto da obra em que a produção artística se inspira mantém relações com o texto inicial (PLAZA,1987).

Não há intenção de mensurar quanto do poema original está nesta nova modalidade. Esta não é uma tradução livre, pois a essência é mantida, e sim uma transcriação, termo que emprestamos de seu criador Haroldo de Campos (2010) que o aplicou na transcriação de poesia para poesia. A noção de transcriação é muito apropriada a produções que vinculam diferentes mídias, e hoje é bastante utilizada nos estudos de criação/ produção cênica ligados a textos literários. Os princípios de buscar a postura de fidelidade, e manter a essência do texto base são objetivos deste processo. As transformações existem, o que permite maior liberdade por não haver a ilusão do literal. Assim, aqui intentamos oferecer uma possibilidade de produção, investigação e negociação de sentidos como criação artística por meio do corpo, que gera argumentos capazes de comunicar a palavra pelo não verbal.

O encontro com Soneto 12 provocou muitas reflexões e aguçou percepções que podem ser ricas como experimentação sensório-motora na concepção e produção cênica. O trabalho artístico pretendido não se reduz à transição de um sistema de signos para outro. O poema está presente em cena, por uma voz que o declama e através da corporeidade. Trabalhar o soneto pela perspectiva do corpo vem de encontro ao pensamento contemporâneo, que cada vez menos se reduz a algo estético gerado através de seu movimento.

O corpo é estudado pelas artes cênicas e pela dança não como objeto/instrumento de arte, mas como um universo interpretativo e metafórico, uma combinação do sensorial e do intelectual. Por este motivo, há a tendência de uma dança mais plural e permeável, em constante troca com as esferas cultural, antropológica, política, tecnológica, psicológica, intelectual e artística. O corpo assume-se como parte integrante e indissociável do entendimento do fazer artístico/ intelectual atual, colocando assim teoria e prática lado a lado. Na prática, é marcante a impossibilidade de uma separação mente/corpo, corpo/mente, corpo/cérebro.

A leitura do texto já provoca sensações e ações no corpo que está o tempo todo em negociação com novos sentidos. A palavra é o incentivo para nossa investigação, pois através desta busca-se produzir com e no corpo uma rede de predisposições perceptuais, motoras, emocionais e de aprendizado. $\mathrm{O}$ corpo em movimento busca compreensões que emergem no seu fazer-dizer.

Ao se apropriar da palavra shakespeariana muitas questões enquanto composição e interpretação surgem. As reflexões sobre a forma e os temas são potência criativa na composição da cena. O Soneto 12, diferentemente das peças do autor, provavelmente não foi criado com intuito de se apresentar em cena. Conceber uma leitura/interpretação corporal do soneto na cena permite uma chave de leitura do soneto que gera questões pertinentes não restritas a esta produção específica, mas também a proposições e/ou produções que buscam o caminho da intermidialidade.

Para embasar esta pesquisa, buscou-se então, teóricos que viessem de encontro ao pensamento que prevê novas possibilidades e transformações: teoria corpomídia de Katz e Greiner (2005), estudos interartes de Clüver (1997), intermidialidade de Müeller (2010), metáforas do corpo de Rengel (2012), Fazer-dizer do corpo 
de Setenta (2008), pensamento metafórico de Lakoff e Johnson (2002) entre outros.

A relação entre corpo e texto, dança e poesia é pensada nesta produção nos preceitos de intermidialidade. Para Clüver (1997) já faz tempo que nos distanciamos de um paradigma que insiste em tratar o texto como um absoluto em detrimento dos seus vários contextos. As artes, mesmo que consideradas autônomas e divididas pelas suas diferentes expressões e contextos, sempre conversaram entre si. Nos primórdios da história da literatura havia muito comparativismo, e é relativamente recente o estudo das produções que integram duas ou mais linguagens artísticas.

Como experiência que mescla áreas de conhecimento - dança e literatura-, um dos nossos eixos condutores está ancorado nos estudos interartes, que restringe seu escopo para a reconstrução das interações entre as artes e os processos de criação artística. Não é somente a palavra que transforma o corpo, este também transforma a palavra do poema. Assim, as conexões pertencentes a um e ao outro são responsáveis pelas relações que são concebidas, e pela nova forma que este produto comunica.

\section{Dança, corpo e temporalidade}

Tendo como base a teoria da arte da fala de Austin, vemos que a linguagem é uma forma de ação, capaz de transformar, já que é produtiva e não imitativa (SETENTA, 2008, p.18). Os estudos contemporâneos consideram o corpo como algo permeável, que realiza trocas com o ambiente, e não um instrumento no qual o movimento expressa. Para Setenta, o corpo pode ser considerado um tipo de linguagem, e portanto "a ênfase no agir ao invés de descrever traz um modo de organização de fala que remete a uma certa configuração típica do corpo"( SETENTA, 2008, p.21).

Estas ideias dialogam com a teoria corpomídia de Katz e Greiner (2005) de que corpo é uma mídia de si mesmo, uma matriz de comunicação e cognição, reforçando o conceito da linguagem como forma de ação.

Dançar este soneto não é limitá-lo a uma única interpretação ou reduzi-lo ao corpo imaginário no poema, a ação de dança-lo é a necessidade de levantar questionamentos e encontrar soluções provisórias. Nas palavras de Setenta (2008) o corpo se organiza e comunica no seu fazer-dizer.

Ao pensar sobre o tempo, a questão central do poema, é importante ter em mente que a linguagem do Soneto 12 pode ser concebida em vários tempos verbais. Este foi escrito em outro tempo, mas que ainda sim se atualiza, e se constrói provisória e continuamente a cada instante, pois trata de uma reflexão humana recorrente.

A dimensão do tempo universal, passa pela percepção corporal, e também particular, cultural e social. Estas são feitas de imagens particulares que podem ser reconhecidas e também comunicadas. Neste soneto, por exemplo, o tempo é sentido eu lírico pela observação da natureza de sua própria existência. É com angústia e aceitação que ele reflete sobre a sua percepção temporal, que é cíclica, tão singular quanto convencional.

No poema prevalecem imagens relacionadas ao Tempo, a sua passagem inexorável, e à mortalidade: o relógio, o dia transformado em noite, a flor murchando, a árvore sem folhas e o outono. Nos dois primeiros quartetos do soneto temos a descrição da relação tempo-natureza e, vale notar, o efeito constante deste sobre a flora que é aceito como impacto consequente e irremediável. No início do terceiro quarteto, o eu-lírico inclui o belo jovem no rol do que irá perecer com a passagem do tempo: "Then of thy beauty do I question make." A maneira como essa perda - da beleza do amado - poderia ser remediada é a procriação. Se o jovem tivesse filhos, uma parcela de si poderia ser reproduzida e, de alguma maneira, eternizada: é esta a esperança que permanece por sugestão do dístico final.

Pensar sobre o contexto temporal que a palavra do poema proporciona é um dos principais questionamentos desta criação cênica. Estes se desdobram em alguns núcleos coreográficos que partem de elementos como: a sensação do tempo, as metáforas criadas, o ritmo da métrica.

Katz e Greiner (2005) defendem que as informações se transformam e se organizam na forma de corpo, fazendo com que este viva num estado de sempre-presente. Vale ressalvar que o corpo em cena é o de um sujeito agente, que por sua vez é constituído de outros sujeitos. Logo, por mais que o corpo que dança esteja sempre no contexto presente, é também carregado de passado, seja por experiências, memórias, tradições e pela própria cultura.

A dança, então, é uma linguagem que se codifica em muitas línguas, que se transforma e comunica. A essência do soneto nesta nova modalidade permite que não fique preso num tempo remoto, e sim em um es- 
tado presente, perpetuando por gerar novas e descobrir antigas leituras, tanto para o dançarino quanto para o espectador, em uma ação quase que conjunta. O poema permanece no fazer-dizer do corpo.

O corpo em cena jamais referencia o futuro como um texto escrito. Este pode utilizar recursos semânticos para direcionar o leitor em um contexto de futuro, mas o corpo em cena não possui estes recursos. O que ambos, texto e corpo, têm em comum é que o momento da ação é capaz de transformar e este novo dizer pode transpassar o momento presente. Ao repetir a ação, esta já estará atualizada e transformada, passível de outras configurações e entendimentos.

Mesmo que tenhamos uma experiência com o tempo, como a vida e a morte, como o começo e o final de um espetáculo, por exemplo, insistimos em manter a noção de repetição de eventos; de resgate da memória; de recontagem de compassos em dança; de voltar atrás no tempo. Há uma direção temporal em que os eventos acontecem - o tempo da realização cênica - mas é uma direção evolutiva (no sentido darwiniano, ou seja, evolução é igual à transformação). (RENGEL, 2012, p 22).

Ao transcriar um poema no corpo, deve-se levar em consideração que, já no momento da leitura, relações são feitas e as novas informações recebidas são processadas, negociando com as informações que já residem no corpo (experiências, percepções, vivência). Dá-se então uma nova organização corporal, que por sua vez, é transitória.

A dança desaparece no exato momento em que é vista. Em outras palavras, o movimento produzido pelo corpo é sempre tido como novo e por mais que se busque a repetição de uma ação ela já é uma informação transformada no/pelo corpo. Portanto, é "impossível resgatar o tempo da dança e recuperar um movimento já executado" (PEREIRA in STUART, 1998, p. 191)

Contrapondo a visão tradicional da metáfora somente como figura de linguagem, o linguista, George Lakoff e o filósofo Mark L. Johnson apresentam a teoria da metáfora conceptual. Em Metáforas da vida cotidiana (2002), eles propõem o entendimento de metáfora como a maneira que percebemos e sentimos o mundo.

Para Lakoff e Johnson (2002), a inter-relação entre corpo, mente e ambiente cria a noção de "embodiment" termo que designa a mente encarnada/corporificada, ou seja, mente processada através das experiências corporais. A dança é capaz de reforçar, criar e recriar significados através de ações corporais que se apresentam de maneira provisória e dependem da forma a qual nos relacionamos com eles. A relação se cria através das experiências que proporcionamos ao aparato sensório-motor que propicia o aprendizado através da visão, tato, audição e do movimento que apresenta papel fundamental no conhecimento do ambiente e do próprio corpo.

o propor movimento através do corpo para o Soneto 12, as interpretes criadoras se apropriam de metáforas que estão infiltradas na vida cotidiana. A investigação no arcabouço pessoal fomenta respostas motoras aos estímulos provocados pelo poema. Memórias, imagens, sentimentos, cheiros, texturas e sons devem ser acessados no/e pelo corpo a fim de comunicar metaforicamente o soneto em dança uma vez que seu entendimento advém de fenômenos do mundo em termos humanos. Lakoff e Johnson (2002) chamam este entendimento como personificação, e é vista por como um tipo específico de metáfora ontológica que é bastante clara no soneto 12.

A passagem do tempo pelo eu-lírico se apresenta como uma comparação entre o homem e a natureza. A exemplo disso, no sétimo e oitavo versos temos: "And summer's green all girded up in sheaves / Borne on the bier with white and bristly beard", que relaciona o embranquecer da barba com a grama verde que perde seu viço. O tempo é o se ecoa em um fluxo inestancável, observável tanto na humanidade quanto na natureza. $\mathrm{O}$ Soneto 12 usa a palavra como metáfora do tempo; sua percepção é, por um lado, a de algo de essência constante e inacabável e por outro, aquilo que e se transforma e se repete.

As ações (que partem dos questionamentos e experimentações corporais) se organizam em núcleos coreográficos, cada qual com diferentes intenções. Na transcriação, utilizou-se a tática de Haroldo Campos que se aproxima e afasta do texto, buscando "a raiz da palavra para depois desenraizá-la, de buscar o centro para depois deslocá- lo" (NOBREGA, 2006, p 252-253). Isto resultou em sensações que despertam e potencializam ações motoras e procedimento para composição coreográfica. Dividiu-se em núcleos coreográficos que são: a) temas: o tempo, a espiral, o ciclo, a passagem, a repetição, os rastros da movimentação, condensação e expansão.

b) Interação: trocas com o ambiente e seus fenômenos; o que estes proporcionam e o que o corpo os proporciona. Exemplo: o quente e o frio, o sol e a sombra, os sons e cheiros e o atrito com diversas texturas. c) Aceleração e desaceleração: Aceleração, pausa e recuperação, movimentos contínuos e contidos em desloca- 
mentos pautados no ritmo da palavra em cena.

A possibilidade de uma escrita metafórica do corpo, presentifica a memória na experiência da dança percebida pelo espectador que, portanto, também tem participação na produção de sentidos: ele compõe o seu poema com os elementos do poema que tem a sua a frente. A palavra em cena se constrói por pontes de comunicação através de metáforas, sejam elas poéticas, corporais, da vida.

As metáforas se realizam no corpo através do ritmo, repetição e transformação. O verbal e o não verbal da palavra coabitam na tentativa de refletir sobre o tempo e sua irreversibilidade tanto na vida quanto na dança. "Nossas atitudes, nossas danças não têm volta, não há como repetir de novo. Repetir é repetir com o novo e não de novo.” (RENGEL,2012, p29).

\section{Consideraçãoes finais}

O desenvolvimento do projeto de transcriação do Soneto 12 de Shakespeare para a cena permitiu um questionamento sobre o papel da literatura e das outras artes, e a importância destas como áreas de conhecimento. Além disso, estimulou a continuidade no campo de pesquisas de intermidialidade, instigando novas trancriações de outros poemas.

A transcriação do poema não se restringiu à teoria, as inter-relações de linguagens artísticas provocaram desdobramentos e articulação de novos sentidos. A teoria serviu como instrumento, mecanismo e elemento de reflexão, portanto não reprimiu a produção, já que nunca foi intuito moldar-se à ela.

O Soneto 12 é reconhecido por sua capacidade de comunicar com as palavras de maneira sensível, e que ainda hoje mantém seu sentido. É ainda mais admirável quando analisado minuciosamente, pois traz a sensação de simplicidade que perpassa pela compreensão de tempo na existência humana - efêmera e perpétua.

Trabalhar com essa infinitude no meio de tantas transformações e alternativas, e ainda manter a essência deste soneto foi um grande desafio. Por ser de natureza teórica-prática, a pesquisa mostrou-se enriquecedora por ampliar possibilidades e permitir novas chaves de leitura do poema pelo viés da corporeidade.

A palavra que transforma o corpo transforma a palavra do poema. Recriá-lo, então, sensibiliza e comunica não só as intérpretes criadoras, mas também a quem perceber a palavra através destes corpos. Esta concede a provisoriedade e a liberdade da interpretação como ação cênica, permitindo que produto seja um processo de expressão poética. O tempo como palavra em cena se fez como corpo e poesia.

Agradecimento: Ines Saber de Mello agradece à Projeto Shakespeare Digital - UFPR/MIT pelo apoio recebido para a realização desta pesquisa.

\section{Referências}

CAMPOS, H. A arte no horizonte do provável. São Paulo: Perspectiva, 2010.

CLÜVER, C. Estudos interartes: conceitos, termos, objetivos in Literatura e Sociedade. n. 2 1997. Disponível em < http://www.revistas.usp.br/ls/article/view/13267> Acesso em 28/11/2014.

GREINER, C; KATZ, H. Por uma teoria do corpomídia. In: GREINER,Christine. O corpo: pistas para estudos indisciplinares. São Paulo. Annablume,2005

JAKOBSON, R. Lingüística e comunicação. São Paulo: Cultrix, 1999.

LAKOFF, G. \& JOHNSON, M. Metáforas da vida cotidiana. Mara Sophia Zanotto (coord. e trad.). São Paulo: Mercado das Letras, 2002.

LEÃO, L e SANTOS, M. S. (org.) Shakespeare, sua época e sua obra. Curitiba: Beatrice, 2008.

MÜELLER, J. E. Intermediality and Media Historiography in the Digital Era.1 
University of Bayreuth (Germany) 2010

NÓBREGA, T. M. Transcriação e hiperfidelidade. Cadernos de Literatura em Tradução. Brasil, n. 7, p. 249-255, nov. 2006. ISSN 1981-2558. Disponível em: <http://www.revistas.usp.br/clt/article/view/49417>. Acesso em: $28 / 11 / 2014$.

PLAZA, J. Tradução intersemiósica. São Paulo: Perspectiva, 1987.

RENGEL, L. Dança: escrita metafórica do corpo como linguagem que traz a memória traçada. In Dança, Salvador, v. 1, n.1 p.19-30 jul-dez 2012

SETENTA, J. S. O fazer dizer do corpo: dança e performatividade. Salvador: EDUFBA, 2008.

SHAKESPEARE, W. 154 Sonetos. RJ: Ibis Libris, $1^{\text {a }}$ edição, 2009. Trad: Thereza Christina Rocque da Motta.

STUART, I. A experiência do Judson Dance Theater. In lições de Dança 2. Pereira Soter (org.). Rio de Janeiro, Univercidade Editora, 2000

TÁPIA, M e NÓBREGA,T. M. (org.) - Haroldo de Campos - transcriação. São Paulo: Perspectiva, 2013. 